\title{
AUTOMATIC NOZZLE CONTROL SYSTEM WITH ULTRASONIC SENSOR FOR ORCHARD SPRAYERS
}

\begin{abstract}
Zeki ZÜREY ${ }^{1}$, Kadir SABANCI ${ }^{2}$, Selami BALCI ${ }^{3}$
Some improvements are needed in spraying with orchard sprayers. During the spraying process, it is also applied in the spaces between trees of cases where the tree spacing is high. For this reason, extra pesticides are consumed and harmful substances are added to the soil. Thus, the production costs increase and efficiency decreases, and also pesticide residues transferred from soil to crops cause health problems. In this study, ultrasonic sensors are placed on the right and left surfaces of the machine facing the tree. With the help of these sensors, the pesticides are sprayed as long as an object is detected within a certain distance. Spraying is stopped when the object is not detected, and this operation is carried out automatically. The developed system consists of an electronic control unit, solenoid valves, and ultrasonic sensors, controlled by a microcontroller. Thanks to this automatic control system, high rates of savings are achieved in pesticide consumption and the addition of harmful substances to the soil is prevented. In addition, thanks to the its compact structure, it can be easily mounted on existing sprayers that are controlled manually.
\end{abstract}

Key words: Orchard sprayer, spraying, automatic control, ultrasonic sensor.

\section{Introduction}

An increase in the world population triggers the rise of needs to meet the demands in agricultural production. The use of pesticides is inevitable for high efficiency in agricultural production [1]. The fact that agricultural areas are limited, and agricultural trade has a large share in the domestic economies of nations has revealed the concept of sensitive agriculture. The main purpose of precision agriculture is to increase the quality of production and concurrently to reduce cost. It aims to prevent waste of resources, increase the gross return of the product and minimize environmental pollution caused by production with the use of advanced information and control systems. Precision farming techniques can be used in every period of agricultural production, from tillage to harvest. In the practice, these techniques can be used in soil analysis, cultivation, planting, fertilization, spraying, monitoring the crop conditions and harvesting more effectively [2].

There has been significant progress in the electronics industry according to the technological revolution. In devices such as sensors, semiconductor switching elements, microcontrollers, software,

\footnotetext{
${ }^{1}$ Department of Electrical\&Electronics Engineering, Karamanoglu Mehmetbey University, Karaman, Turkey, (zurey.z@gmail.com) https://orcid.org/0000-0003-4219-1274

2 Department of Electrical\&Electronics Engineering, Karamanoglu Mehmetbey University, Karaman, Turkey, (kadirsabanci@kmu.edu.tr) (DiD https://orcid.org/0000-0003-0238-9606

${ }^{3}$ Department of Electrical\&Electronics Engineering, Karamanoglu Mehmetbey University, Karaman, Turkey, (sbalci@kmu.edu.tr) https://orcid.org/0000-0002-3922-4824
} 
internet applications, efficiency has increased while costs have been reduced [3]. Furthermore, low cost automatic control systems, tracking systems, and management systems have become more common.

Spraying is used as a common solution in order to increase yields and obtain higher quality products in nurseries and gardens. Also, it has an important effect on fruit disease and pest control, is an essential part of orchard applications [4]. Tree shapes and sizes differ significantly by time and region. These differences require that the amount, speed, and direction of the pesticide sprayed be adjusted specifically for each zone. As a result of these adjustments not being made specifically to the region, they caused serious pollution in the environment and excessive pesticide residue threatening the safety of agricultural products $[5,6]$.

To increase efficiency in spraying, it is necessary to identify the tree using sensor technologies, and then apply the appropriate amount of material [7, 8]. Ultrasonic sensors are widely used in automatic spray systems due to their economical convenience and ease of use [9]. In the literature; He et al. developed a system that converts a continuous spraying system into an automatic sprayer using infrared sensing technology. In apple orchards, this system can save range of 50\% -75\% pesticides [10]. Esau et al. using four cameras, designed a variable spraying system through image processing, detecting diseases in blueberry leaves. Solanelles et al. using ultrasonic sensors and proportional solenoid valves, he designed an electronic control system prototype for a variable rate sprayer based on tree width $[11,12]$. Zhai et al. to detect the tree profile in real-time, installed a platform using an ultrasonic sensor. The experiments carried out showed $92.8 \%$ measurement accuracy for normal tree canopy and $90.0 \%$ for cherry tree canopy [13]. Jeon et al. developed a real-time, variable speed sprayer that automatically adjusts spray outputs according to the canopy size using ultrasonic sensors at $20 \mathrm{~Hz}$ detection frequency and the proportional solenoid valve $[8,14]$. Zaman and Salyani measured the canopy of trees using ultrasonic sensors. It was observed that there was $82.63 \%-128.71 \%$ difference between the measurements made with the developed system and manual measurements [15]. Gil et al. developed an orchard sprayer supplemented with airflow using ultrasonic sensors $[16,17]$. Moltó et al. used three ultrasonic sensors to determine geometric properties in citrus fruit trees. This application allowed the spraying to be applied at three different flow rates according to a canopy width measurement with an ultrasonic sensor [18]. Llorens et al. by applying the variable rate method, they has achieved 58\% savings in pesticide consumption and obtained better spraying efficiency in leaves compared to air blower orchard sprayer [19]. Tumbo et al. used ultrasonic sensors to estimate the most necessary geometrical parameters of trees and compared these with manual measurements [20]. It is observed that many different types of sensors have been preferred, especially infrared (IR) sensors, Light Detection and Ranging (LIDAR) sensors and ultrasonic sensors from the previous studies. However, a couple of limitations were found, such as the need for a computer to run a LIDAR sensor and poor performance of IR sensors [21].

In this study, it is aimed to prevent health problems and financial losses that occur when orchard sprayers continuously spray. An economical and versatile electronic control system that provides automatic control of the orchard sprayers has been developed to prevent pesticide residues from falling into the soil. Thanks to this control system, the cost of spraying decreases, efficiency, and quality increases. Ultrasonic sensors are used to detect the trees to be sprayed in the developed system. These sensors and the rest of the system are managed with a microcontroller. Thus, it provides a great economic advantage with a reasonable price, and also overcome the issues caused by the hardware crowd. 


\section{Orchard Sprayers}

Many different sizes of garden sprayers with various features are produced. The primary purpose of these machines is to spray the pesticide stored in a tank into the trees [22].

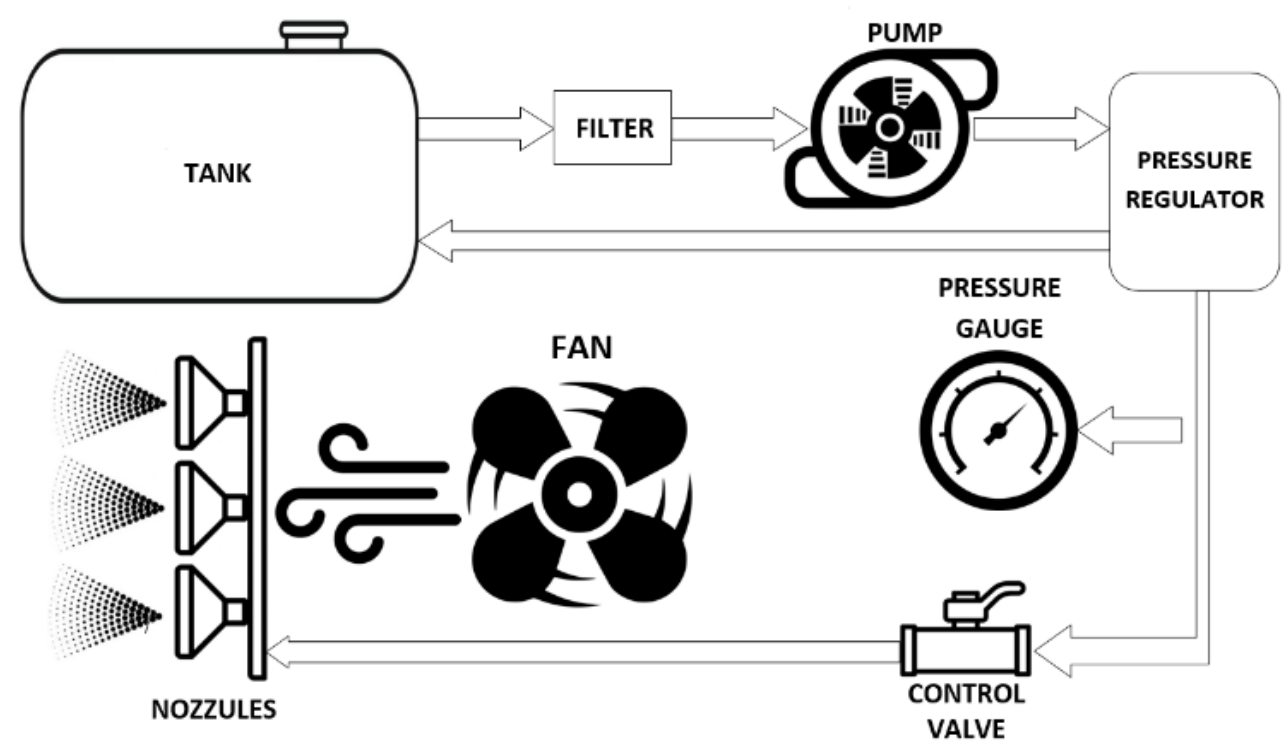

Figure 1. Orchard sprayer components

System components of orchard sprayers are shown in Figure 1. The pesticide is filled into a tank. Afterward, the filled pesticide is transferred to the filter. Then, residues and foreign substances in the pesticide are filtered in the filter. After passing through the filter, the pesticide is transferred to the pump, which is powered by the tail shaft and provides the necessary pressure for the spraying process. A pressure regulator is then used to control the pressure in the system. This regulator lowers the high pressure by sending some of the pesticides back to the tank, and thus it can control the pressure. A pressure gauge is installed at the outlet of the pressure regulator so that the operator can monitor the system pressure. The pesticide coming out of the pressure regulator comes to the unit where the control valves are located. The valves are opened and closed to deliver the pesticide to the desired nozzles. Reaching the nozzles with high pressure, the pesticide is sprayed homogeneously. A high-power fan is installed behind the nozzles. It is ensured that the sprayed pesticide is delivered to more distant places thanks to airflow caused by the fan. Eventually, pesticide loss that falls to the soil before it reaches the tree is prevented.

\section{Automatic Nozzle Control System}

In orchard spraying machines, the spraying process continues without interruption since the operator starts spraying. This situation causes extra pesticide consumption in the gardens where there is a large space between trees. To prevent this, the automatic nozzle control system has been developed. The system can control four zones as right down and up or left down and up. 


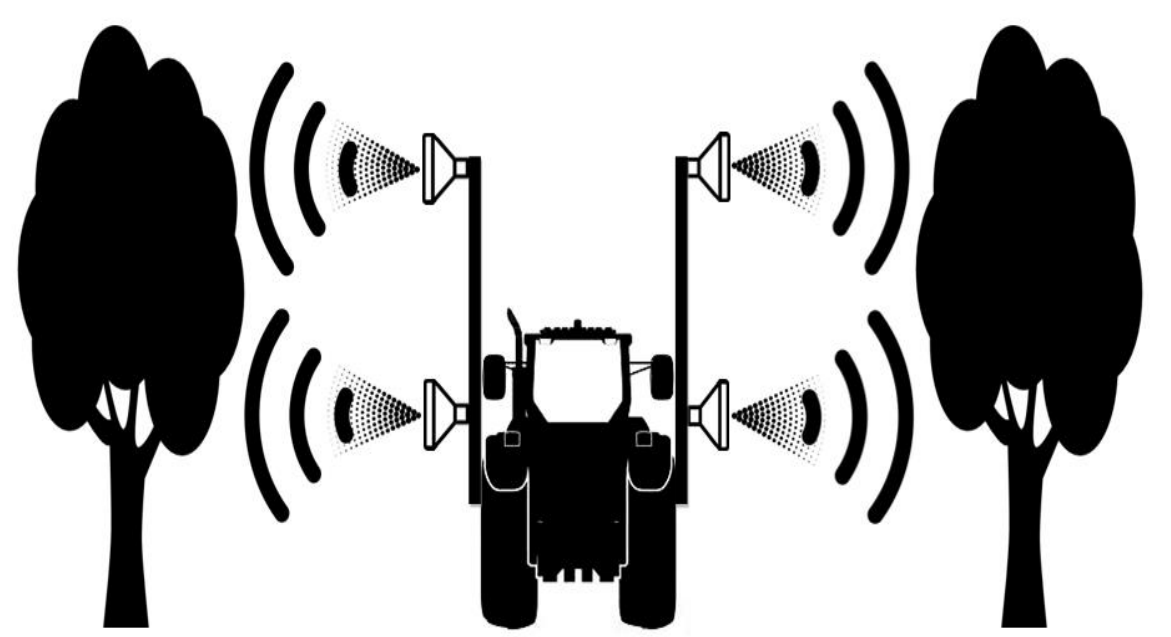

Figure 2. Automatic nozzle control system

The developed system consists of four ultrasonic sensors, four 3-ways solenoid valves, and a motherboard. It can be attached to newly produced spray machines, or it can be easily integrated into the sprayers that are already in use.

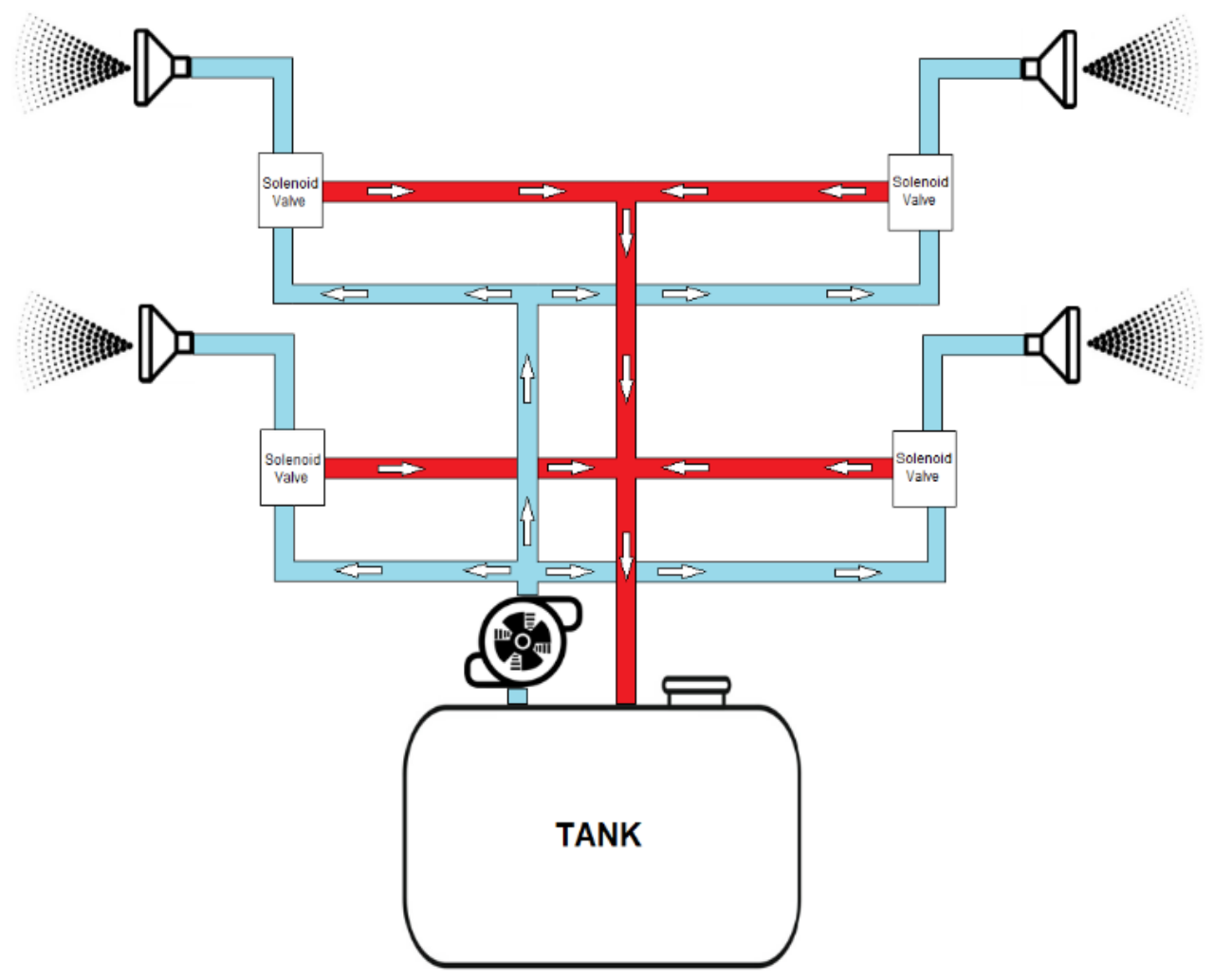

Figure 3. System schema

In orchard sprayers, these nozzles need to be controlled swiftly. Otherwise, it may cause extra pesticide consumption and may cause some of the trees not to be sprayed. For this reason, it is not appropriate to prefer electric motorized ball valves. Unlike electric motorized ball valves, solenoid valves open and close swiftly. 


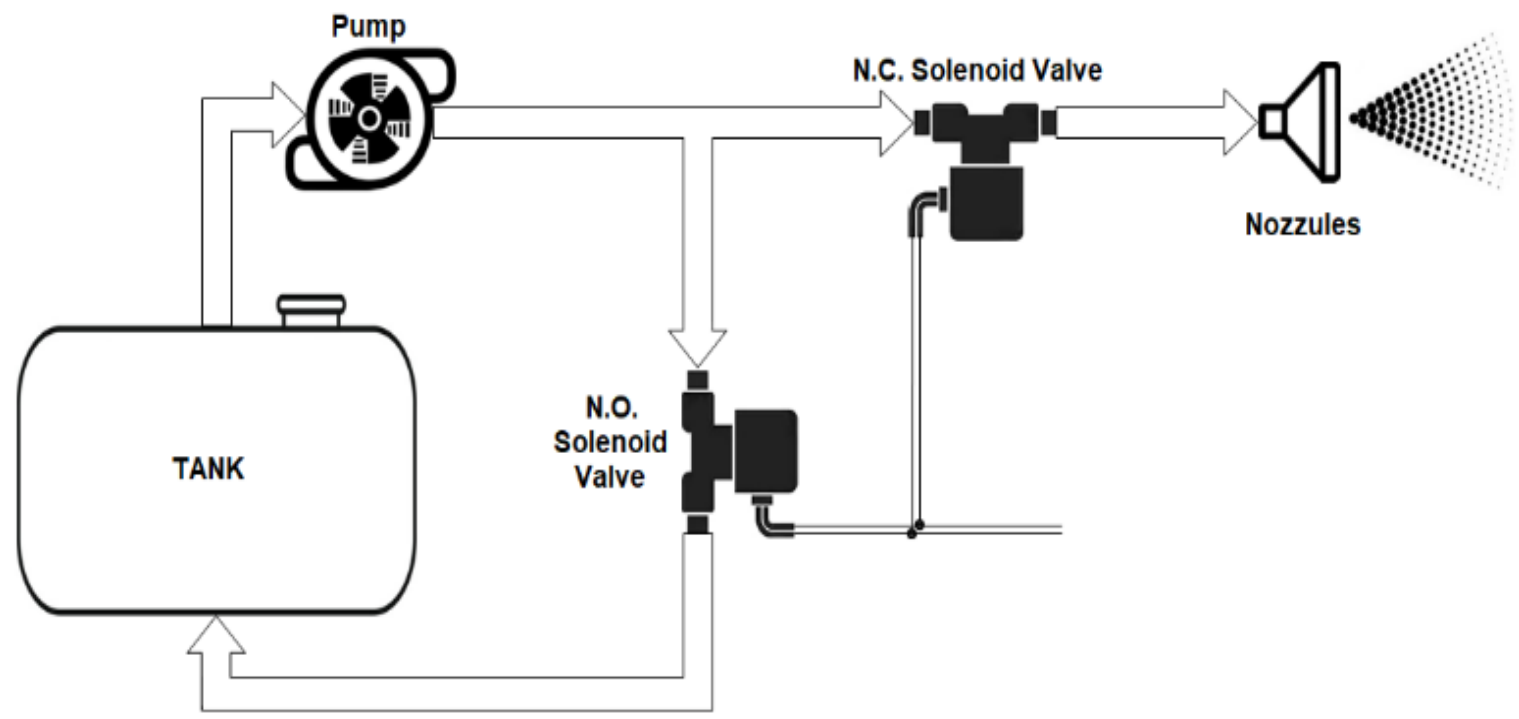

Figure 4. Solenoid valve scheme

The pesticide, whose pressure is increased with the pump, should be discharged to the tank when it is not transferred to the nozzles, that is when the spraying is stopped. Otherwise, system pressure will increase excessively and will cause damage to some parts, especially the pump. Therefore, a 3-way valve was used to control the spraying. The pesticide entering the valve will either be transferred to the nozzles or discharged back to the tank. However, the use of 3-way solenoid valves is not common and healthy. Alternatively, a "T" connection was designed as shown in Figure 4 using two solenoid valves, one normally open and the other normally closed.

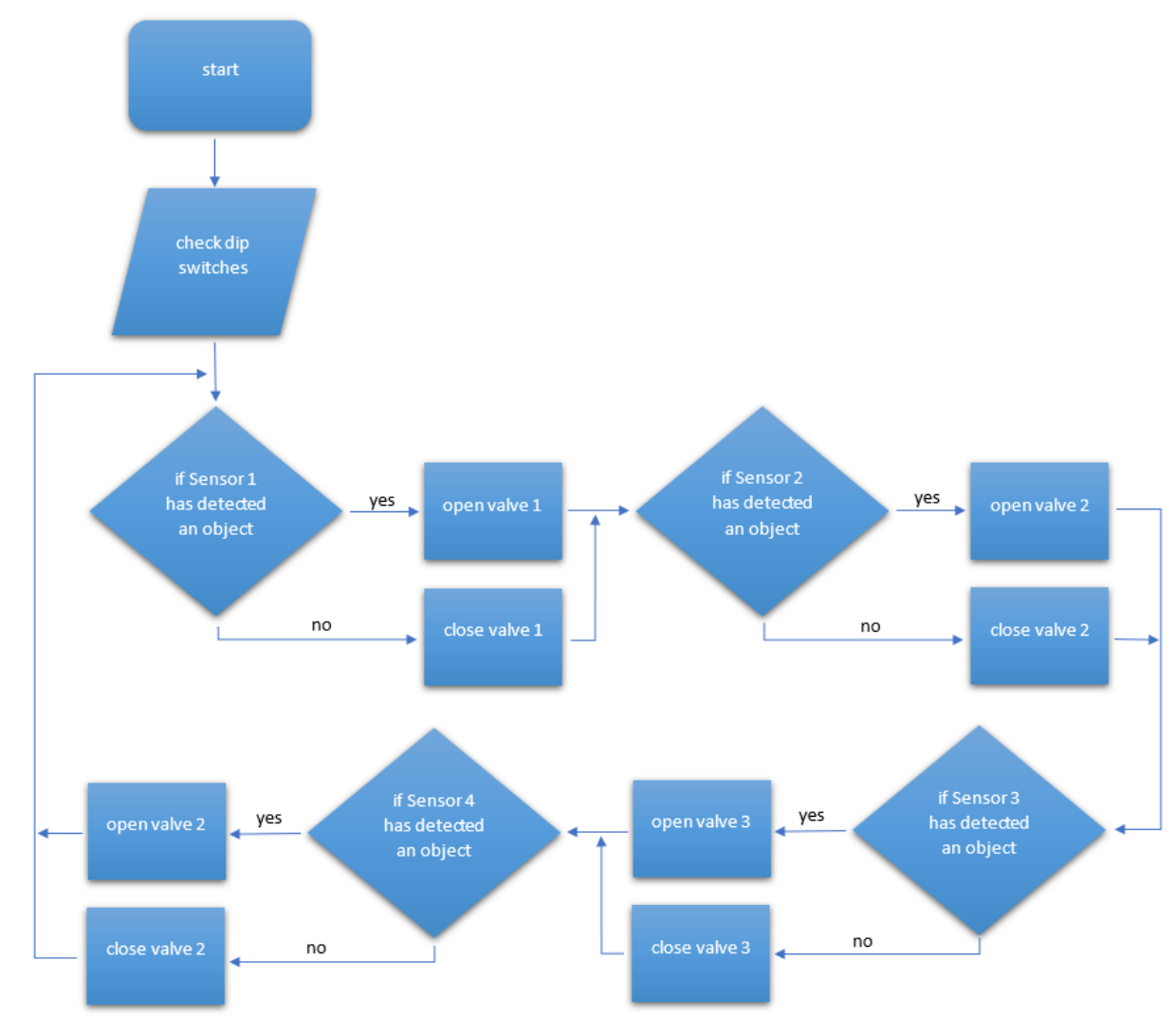

Figure 5. Program flowchart 


\section{Ultrasonic Sensor}

There are two basic criteria that make it reasonable to prefer ultrasonic sensors among the other options. The first criteria is the sensing distance; an ultrasonic sensor is expected to accurately measure the distance from the object in front of it. The second criteria is the view angle; ultrasonic sensors have a cone-shaped sensing area as they send sound waves and follow the rotating sound signals. Sensors with a wide view angle cannot detect small objects because they will scan a wide area. This condition may create a major problem for users. Therefore, a good ultrasonic sensor is expected to have a narrow viewing angle [23].

There is no such thing as the distance determination of the ultrasonic sensors that are intended to be used for orchard sprayers. It is sufficient to detect whether there is a tree within a certain distance. Since the objects to be perceived are trees, there is no need for a narrow view angle. Any industrial grade ultrasonic sensor with an IP68 certificate can be used in orchard sprayers. This provides a significant advantage in terms of cost.

Ultrasonic sensor with the code "JSN-SR04T" is preferred in the developed system [24].

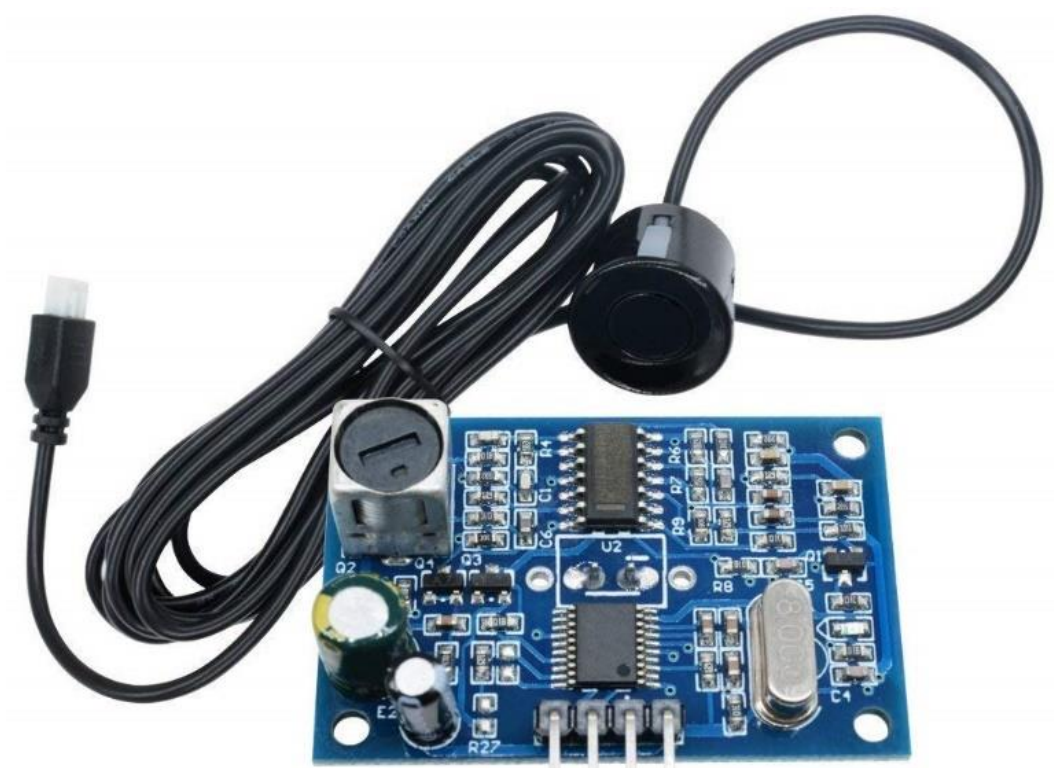

Figure 6. JSN-SR04T ultrasonic sensor

Table 1. JSN-SR04T ultrasonic sensor parameters

\begin{tabular}{cc}
\hline Communication & Pulse width output / Serial output \\
Operating voltage & DC $3.0-5.5 \mathrm{~V}$ \\
Working current & $<8 \mathrm{~mA}$ \\
Probe frequency & $40 \mathrm{kHz}$ \\
Farthest range & $600 \mathrm{~cm}$ \\
Recent range & $20 \mathrm{~cm}$ \\
Distance accuracy & $\pm 1 \mathrm{~cm}$ \\
Resolution & $1 \mathrm{~mm}$ \\
Measuring angle & $75^{\circ}$ \\
Enter the trigger signal & $1-10 \mu$ s above the TTL pulse \\
Output the echo signal & $2-$ the serial port to send instructions 0 X55 \\
Wiring & Output pulse width level signal or TTL \\
& $3-5.5 \mathrm{~V}$ ( power positive ) \\
\hline
\end{tabular}




\begin{tabular}{cc}
\hline & Trig ( RX ) \\
& Echo ( TX, output) \\
Product size & GND ( power negatif ) \\
Operating temperature & $42 \mathrm{~mm} \times 29 \mathrm{~mm} \times 12 \mathrm{~mm}$ \\
\hline
\end{tabular}

The probe and board of the ultrasonic sensor are housed in a box with mounting stand with IP68 certification. In this way, it is ensured that the sensor is protected from external factors, and it is possible to position it anywhere on the machine regardless of the motherboard.

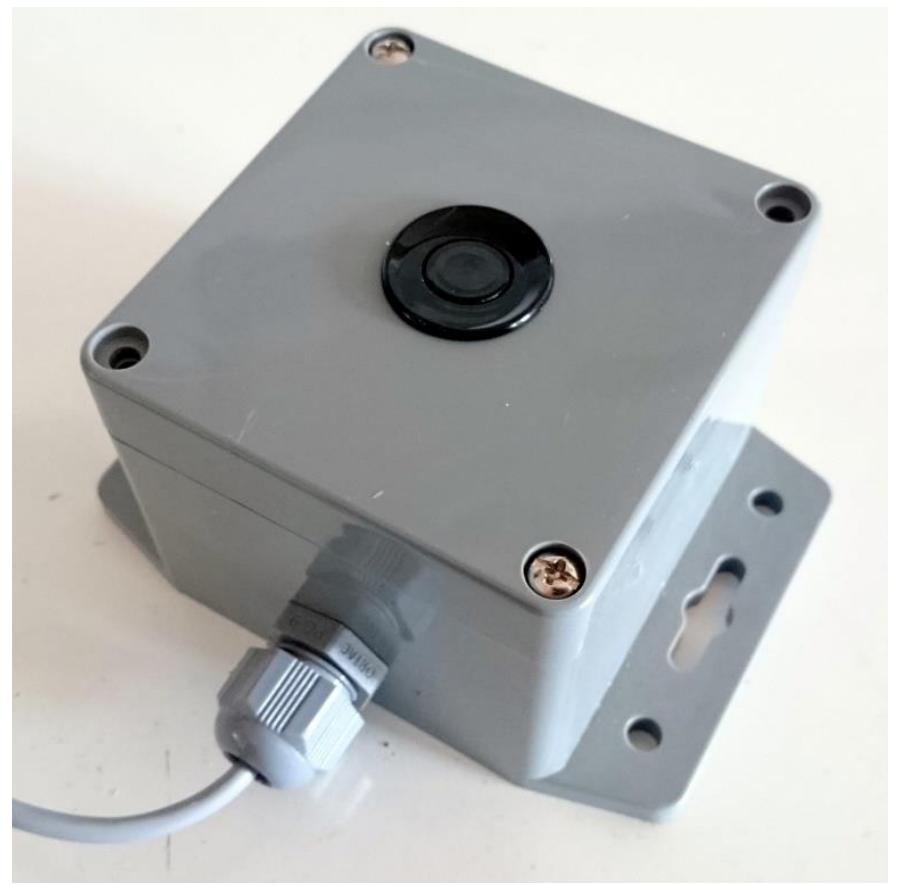

Figure 6. Ultrasonic sensor module

\section{Mainboard}

The PCB is prepared in a laboratory environment. PIC18F45K80 microcontroller produced by Microchip, which is capable of reading four ultrasonic sensors simultaneously [25]. This microcontroller has four external interrupts. This makes it possible to read the echo signals from each sensor.

$\mathrm{N}$-channel MOSFET is used to drive solenoid valves. These MOSFETs can be driven with logic level. In this way, there is no need for any driver IC. It also has a maximum operating voltage of $100 \mathrm{~V}$ and a continuous drain current of $42 \mathrm{~A}$.

A dip switch is preferred to use it manually when necessary. Thus, the nozzles can be opened and closed independently of the sensors with this switch. 


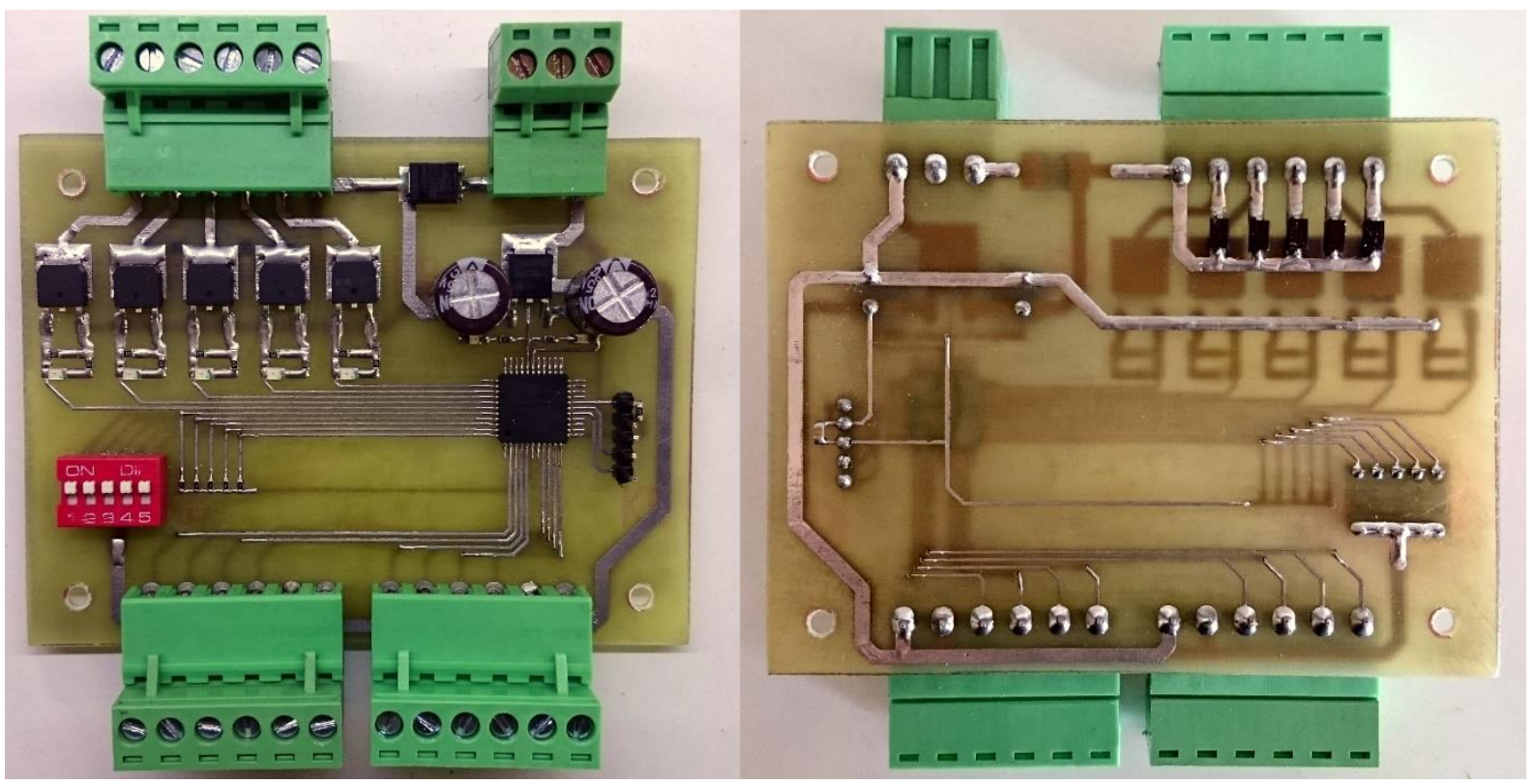

Figure 7. Mainboard top side and bottom side

\section{Results and Conclusions}

In this study, a management system has been developed for automatic control of nozzles in orchard sprayers. It is aimed to spray agricultural pesticides only on trees using an ultrasonic sensorbased system. The main purpose of this system is not to determine the distance to the target, but to determine if there is any object within a certain distance. The practical use of sensors does not require any external computer as in image processing applications. It is an effective solution in terms of detection performance with a low-cost mechanism. Information from the sensors is interpreted in the PIC18F45K80 microcontroller. Thus, the solenoid valves are driven via logic level MOSFETs. In addition, as the drug consumption will decrease with the developed system, the environment and human health will be protected.

The developed pesticide spraying system is tested and investigated the success of the system in laboratory conditions. While there is an object in its range, the spraying system successfully ejects liquid on it. As soon as the object removes from its range, the spraying system stops immediately ejecting liquid. It has been observed that the developed system detects objects within $5 \mathrm{~m}$ distance with high stability. In future studies, the developed system will be installed on a sprayer. In order to determine the decrease in the use of pesticides, the precision spraying system is going to test in practical usage.

\section{References}

[1] Ilica, A. \& Boz, A. F. (2018). Design of a Nozzle-Height Control System Using a Permanent Magnet Tubular Linear Synchronous Motor. Tartm Bilimleri Dergisi, 24, 374-385. doi: 10.15832/ankutbd.456662.

[2] Keskin, M., Say, S., Sekerli, Y. \& Arslan, A. (2018). Hassas Tarim Teknolojileri Ile Saglanabilecek Faydalar. Tarim Türk, 6, 14-17.

[3] Aydin, C., Sabanci, K. \& Unlersen, M. F. (2017). Determination of Seed Volume in the Seed Tank of Pneumatic Precision Seeder by Using Microcontroller Based Control System. International Journal of Applied Mathematics, Electronics and Computers.

[4] Zhang, Z., Wang, X., Lai, Q. \& Zhang, Z. (2018). Review of Variable-Rate Sprayer Applications Based on Real- Time Sensor Technologies. 
[5] Li, L., He, X., Song, J., Liu, Y., Zeng, A., Yang, L., Liu, C. \& Liu, Z. (2018). Design and Experiment of Variable Rate Orchard Sprayer Based on Laser Scanning Sensor. International Journal of Agricultural and Biological Engineering, 11, 101-108. doi: 10.25165/j.ijabe.20181101.3183.

[6] Wei, Z., Xiu, W., Wei, D., Shuai, S., Songlin, W. \& Pengfei, F. Design and Test of Automatic toward-Target Sprayer Used in Orchard. 2015 IEEE International Conference on Cyber Technology in Automation, Control, and Intelligent Systems (CYBER), 8-12 June 20152015. 697-702.

[7] Chen, Y., Zhu, H. \& Ozkan, E. (2012). Development of a Variable-Rate Sprayer with Laser Scanning Sensor to Synchronize Spray Outputs to Tree Structures. Transactions of the ASABE, 55, 773781. doi: 10.13031/2013.41509.

[8] Jeon, H., Zhu, H., Derksen, R., Ozkan, E. \& Krause, C. (2011). Evaluation of Ultrasonic Sensor for Variable-Rate Spray Applications. Computers and Electronics in Agriculture, 75, 213-221. doi: 10.1016/j.compag.2010.11.007.

[9] Esau, T., Zaman, Q., Chang, Y., Schumann, A., Percival, D. \& Farooque, A. (2013). SpotApplication of Fungicide for Wild Blueberry Using an Automated Prototype Variable Rate Sprayer. Precision Agriculture, 15. doi: 10.1007/s11119-013-9319-4.

[10] He, X., Yan, K., Chu, J., Wang, J. \& Zeng, A. (2003). Design and Testing of the Automatic Target Detecting, Electrostatic, Air Assisted, Orchard Sprayer. 19.

[11] Solanelles, F., Escolà, A., Planas De Martí, S., Rosell, J. R., Camp, F. \& Gràcia, F. (2006). An Electronic Control System for Pesticide Application Proportional to the Canopy Width of Tree Crops. Biosystems Engineering, 95, 473-481. doi: 10.1016/j.biosystemseng.2006.08.004.

[12] Solanelles, F., Planas De Martí, S., Escolà, A. \& Rosell, J. (2002). Spray Application Efficiency of an Electronic Control System for Proportional Application to the Canopy Volume. Aspects of Applied Biology, 66, 139-146.

[13] Zhai, C., Zhao, C., Wang, X., Zou, W., Mao, Y. \& Zhang, R. (2010). Probing Method of Tree Spray Target Profile. Nongye Gongcheng Xuebao/Transactions of the Chinese Society of Agricultural Engineering, 26, 173-177. doi: 10.3969/j.issn.1002-6819.2010.12.029.

[14] Jeon, H. \& Zhu, H. (2012). Development of a Variable-Rate Sprayer for Nursery Liner Applications. Transactions of the ASABE, 55, 303-312. doi: 10.13031/2013.41240.

[15] Zamahn, Q. \& Salyani, M. (2004). Effects of Foliage Density and Ground Speed on Ultrasonic Measurement of Citrus Tree Volume. Applied Engineering in Agriculture, 20. doi: $10.13031 / 2013.15887$.

[16] Gil, E., Escolà, A., Rosell, J. R., Planas, S. \& Val, L. (2007). Variable Rate Application of Plant Protection Products in Vineyard Using Ultrasonic Sensors. Crop Protection, 26, 1287-1297. doi: https://doi.org/10.1016/j.cropro.2006.11.003.

[17] K. Giles, D., J. Delwiche, M. \& B. Dodd, R. (1987). Control of Orchard Spraying Based on Electronic Sensing of Target Characteristics. Transactions of the ASAE, 30, 1624-1636. doi: https://doi.org/10.13031/2013.30614.

[18] Molto, E., Martin-Gorriz, B. \& A, G. (2001). Pesticide Loss Reduction by Automatic Adoption of Spraying on Globular Trees. Journal of Agricultural Engineering Research, 78, 35-41.

[19] Llorens, J., Gil, E., Llop, J. \& Escolà, A. (2010). Variable Rate Dosing in Precision Viticulture: Use of Electronic Devices to Improve Application Efficiency. Crop Protection, 29, 239-248. doi: https://doi.org/10.1016/j.cropro.2009.12.022.

[20] Tumbo, S., Salyani, M., Whitney, J., Wheaton, T. \& Miller, W. (2002). Investigation of Laser and Ultrasonic Ranging Sensors for Measurements of Citrus Canopy Volume. Applied Engineering in Agriculture, 18. doi: 10.13031/2013.8587.

[21] Warneke, B. W., Pscheidt, J. W. \& Rosetta, R. Sensor Sprayers for Specialty Crop Production. 2019.

[22] Tewari, V. K., Chandel, A., Nare, B. \& Kumar, S. P. (2018). Sonar Sensing Predicated Automatic Spraying Technology for Orchards. Current Science, 115, 1115-1123. doi: 10.18520/cs/v115/i6/1115-1123.

[23] Onler, E., Celen, I., Kiliç, E. \& Durgut, M. (2014). Design of a Flow Rate Adjustement System Related to Tree Foliage Surface Estimation by Using Ultrasonic Sensors (Smart Spraying Machine). 10.

[24] Jsn-Sr04t ultrasonic sensor. https://www.amazon.com/Ultrasonic-Waterproof-JSN-SR04TIntegrated-Transducer/dp/B07SHLMSVZ (Accessed: 15 July 2020) 
[25] Microchip. Pic18f45k80 Microcontroller.

https://www.microchip.com/wwwproducts/en/PIC18F45K80 (Accessed: 20 July 2020) 